\title{
Pre-pregnancy high-risk factors at first antenatal visit: how predictive are these of pregnancy outcomes?
}

\author{
Barthélémy Tandu-Umba \\ Muela Andy Mbangama \\ Kitenge Marc Brunel \\ Kamongola \\ Armel Georges Kamgang \\ Tchawou \\ Mawamfumu Perthus \\ Kivuidi \\ Sam Kasonga Munene \\ Irène Kambashi Meke \\ Oscar Kapuku Kabasele \\ Bituemi Jackson Kondoli \\ Kibundila Rolly Kikuni \\ Simon Kasikila Kuzungu \\ Department of Obstetrics and \\ Gynecology, University Clinics of \\ Kinshasa, Kinshasa, Democratic \\ Republic of Congo
}

This article was published in the following Dove Press journal:

International Journal of Women's Health

5 December 2014

Number of times this article has been viewed

Objective: To determine relationships between pre-pregnancy risk factors at first antenatal visit booking and pregnancy outcomes.

Study design: This was a multicenter, cross-sectional study involving women admitted for singleton delivery from July 1 until October 31 (3 months), 2013, at nine major maternity clinics in Kinshasa, Democratic Republic of Congo. All women were checked for hereditary, community, and personal medical/surgical risk situations and mother/infant problems in previous pregnancies. Maternal and perinatal complications related to current/just-terminated pregnancy were analyzed according to pre-pregnancy risk factors in order to establish their prediction concerning maternal and perinatal complications related to current/just-terminated pregnancy (odds ratios). Results are given with $95 \%$ confidence intervals, and $P<0.05$ was considered significant.

Results: The study sample comprised 2,086 women. Primiparity (36.5\%), single relationship status (26.4\%), and maternal age $\geq 35$ years $(18.3 \%$ ) were the most important non-pathologic risk factors, while arterial hypertension in family (34.3\%), previous miscarriage $(33.2 \%)$, overweight/obesity $(21.9 \%)$, diabetes in family $(21.1 \%)$, previous cesarean section $(15.7 \%)$, previous postpartum hemorrhage (13.1\%), low birth weight $(10 \%)$, previous macrosomia $(10 \%)$, and previous premature rupture of membranes $(6.2 \%)$ predominated among pathologic risk factors. Major adverse outcomes recurred in some women, with recurrence rates of 21/37 (57\%), 111/208 (53\%), 74/208 (36\%), 191/598 (32\%), 132/466 (28\%), 24/130 (18\%), and 4/65 (6\%) for prematurity, low birth weight, macrosomia, preeclampsia/eclampsia, cesarean section, premature rupture of membranes, and stillbirth, respectively. Outcomes that were significantly influenced by non-pathologic risk factors were also significantly influenced by pathologic risk factors.

Conclusion: Pregnancy adverse outcomes are strongly influenced by either non-pathologic or pathologic pre-pregnancy risk factors at first antenatal visit booking. The recurrence potential of complications is one reason to establish the predictability and preventability of morbidity such that the most appropriate referrals and best options throughout the pregnancy can be determined.

Keywords: pre-pregnancy risk factors, recurrence, maternal/perinatal outcomes, developing countries

\section{Introduction}

Factors that put mother, fetus, or neonate at increased risk of morbidity or mortality can belong to pre-pregnancy situations (pathologic or not) or pregnancy proceeding, including in the postpartum period. ${ }^{1,2}$ Recognition of such risk situations by caregivers permits proper counseling and planning regarding progression of pregnancy and is likely to prevent complications. ${ }^{3,4}$ Although it would be better to capture the overall risk situation, selection systems based on only few factors are still suggested in order

submit your manuscript $\mid$ www. dovepress.con 
to identify a small cohort of women at the highest risk, ${ }^{5}$ which is a very useful strategy in deprived areas where health facilities are scarce for the majority. ${ }^{6}$

Risk factors existing before pregnancy are easy to ascertain at the first antenatal visit, since information is derived from a simple anamnesis. This is particularly suitable in developing countries in which antenatal care is provided by unskilled personnel. ${ }^{7}$ Non-pathologic pre-pregnancy risk factors that have been found to impact pregnancy outcomes include parity (primiparity and multiparity), age $<18$ or $\geq 35$ years, height $\leq 150 \mathrm{~cm}$, and behaviors such as cigarette smoking and drug and alcohol intake, more acting in combination rather than individually. ${ }^{8-10}$ Pathologic pre-pregnancy risk factors relate to complications experienced during previous pregnancies, including miscarriage, premature labor, premature rupture of membranes (PROM), preeclampsia/eclampsia (PEE), postpartum hemorrhage (PPH), cesarean section, infection, disordered fetal growth, fetal/neonatal distress, and perinatal mortality, as well as to currently present medical/ surgical pathologies (hereditary, community, and personal illnesses, including obesity).

Even in developed countries, it is still debated what the standard of antenatal care should be in regard to number and timing of visits and what information is absolutely necessary to obtain, especially in regard to planning of laboratory tests and other investigations. ${ }^{3,11,12}$ Furthermore, in developing countries, poverty and misconceptions about antenatal care that are viewed as more curative than preventive have been basis for no or late antenatal attendance. ${ }^{13-15}$ In Democratic Republic of Congo, official data $^{16}$ have shown relatively high rates of antenatal care attendance ( $85 \%$ in the whole country; $95 \%$ in the capital, Kinshasa) and a rate of skilled assistance at delivery that is as high as $74 \%$ (much less in rural areas). Nonetheless, maternal and neonatal mortality rates remain among the highest in Africa: one in 13 women still dies in pregnancy or childbirth and 42 per 1,000 neonates die before 1 month of age. ${ }^{16}$ Since antenatal surveillance may prevent or treat many complications that can lead to death, current rates indicate that recognition of risk situations by caregivers needs to be revisited. However, a large number of antenatal care attendees are seen only once. ${ }^{16}$ Therefore, for many women, the first antenatal visit may be the last one in which the maximum is expected to be invested. ${ }^{7}$ Our study thus aimed to determine how pre-pregnancy risk factors present at the first antenatal visit booking might predict pregnancy outcomes so as to ensure proper referrals or accurate management in the labor ward.

\section{Study design}

This was a multicenter, cross-sectional study approved by the scientific board of the Faculty of Medicine at the University of Kinshasa, Kinshasa, Democratic Republic of Congo. The study sample consisted of women admitted for singleton delivery from July 1 until October 31 (3 months), 2013, at nine sites of study corresponding to major maternity clinics in Kinshasa, the capital of the country, which has a population of 9 million people. These sites of study were: University Hospital of Kinshasa; Provincial General Hospital; Ngaliema Hospital; Maternity of Kintambo; Bondeko Hospital; St Joseph Hospital; Maternity of Kingasani; Maternity of Binza; and Kimbaguists Maternity. In these maternities, deliveries are assisted by qualified health care professionals (either nurses or doctors). All authors agreed on how to collect the required information on a standard sheet and each of the nine interns listed as coauthors (KMBK, TAGK, MPK, MSK, MIK, KOK, BJK, KRK, and KSK) was assigned to a maternity clinic for data collection.

There were no exclusion criteria, and women were considered for study regardless of whether they had been followed for antenatal care or not. Deliveries were considered as gestational age $\geq 28$ weeks, established using the last menstrual period, ultrasonography, if performed close to the start of pregnancy and a birth weight $\geq 1000 \mathrm{~g}$. Prematurity was considered as gestational age $<37$ weeks, as clinically estimated by a pediatrician. All women were checked for pre-pregnancy risk situations, as mentioned previously: low socioeconomic status, single status or not living with a partner, primiparity, grand multiparity ( $\geq 5$ ), age $<18$ or $\geq 35$ years, height $\leq 150 \mathrm{~cm}$, personal medical/ surgical morbidities, and mother/infant problems in previous pregnancies. Previous miscarriage was defined as at least two previous spontaneous abortions (consecutive or not). Physical abnormalities and maternal and perinatal complications related to current/just-terminated pregnancy were recorded. Overweight/obesity was specially defined as postpartum body mass index $(\mathrm{BMI}) \geq 28 \mathrm{~kg} / \mathrm{m}^{2}$, according to ranges previously defined in our setting. ${ }^{17}$ Neonatal distress was defined as an Apgar score $<7$ at the fifth minute. Stillbirth was defined as lack of signs of life by Apgar score assessment. Low birth weight (LBW) and macrosomia were defined as birth weight $<2,500 \mathrm{~g}$ and $\geq 4,000 \mathrm{~g}$, respectively.

Irrespective of how each intern exploited individual information from their site in order to fulfill the requirements for the completion of graduation in medicine, one of the authors (Dr Mbangama) checked each participant's data for validation before their inclusion in a common file using Microsoft Excel 
(Microsoft Corporation, Redmond, WA, USA) 2007. After transfer to SPSS (v 18.0; SPSS Inc., Chicago, IL, USA) for statistical calculations, univariate analyses (odds ratios [ORs]) were stratified by each pre-pregnancy risk factor in a dichotomic way (ie, women had or did not have each risk factor) to establish whether there was significant association with adverse outcomes encountered/recurring during current/justterminated pregnancy. Multivariate calculations (regression) were aimed at isolating factors that were independently associated with occurrence or recurrence of adverse pregnancy outcomes. Results are given with $95 \%$ confidence intervals (CIs), and $P<0.05$ was considered significant.

\section{Results}

The study sample included 2,086 women, whose general characteristics are presented in Table 1 . The vast majority of the women $(1,984$ [95.1\%]) had been admitted at least once to antenatal care and 1,620 (77.7\%) were vaginally delivered $(22.3 \%$ by cesarean section). Cephalic presentation was observed in 1,986 cases $(95.2 \%)$, breech presentation in $73(3.5 \%)$, and transverse lie in $27(1.3 \%)$. No maternal deaths were registered. Socioeconomic status was discarded from the study due to inappropriate registration of items aimed at assessing it.

Among the pre-pregnancy risk factors presented in Table 2, the most prevalent non-pathologic risk factors $(\geq 10 \%$ ) were primiparity (36.5\%), single status or not living with a partner (26.4\%), maternal age $\geq 35$ years $(18.3 \%)$, and grand multiparity $(10.7 \%)$, while the most important pathologic risk factors ( $\geq 5 \%$ ) were hypertension in family (34.3\%), history of miscarriage (33.2\%), overweight/obesity $(21.9 \%)$, diabetes in family $(21.1 \%)$, scarred uterus after cesarean section (15.7\%), previous PPH (13.1\%), LBW (10\%), macrosomia (10\%), and PROM (6.2\%).

Maternal and perinatal adverse outcomes for which the prevalence was $\geq 1 \%$ during current/just-terminated

Table I General maternal and perinatal characteristics of the study sample

\begin{tabular}{ll}
\hline Parameters & Mean \pm standard deviation \\
\hline Age (years) & $28.1 \pm 6.4$ \\
Weight $(\mathrm{kg})$ & $64.4 \pm 12.9$ \\
Height $(\mathrm{cm})$ & $1.60 \pm 0.2$ \\
Postpartum BMI $\left(\mathrm{kg} / \mathrm{m}^{2}\right)$ & $24.5 \pm 4.6$ \\
Gravidity & $2.8 \pm \mathrm{I} .8$ \\
Parity & $2.4 \pm \mathrm{I} .6$ \\
Gestational age (weeks) & $38.4 \pm 2.3$ \\
Birth weight $(\mathrm{g})$ & $3,066.9 \pm 575.3$ \\
Apgar score & $8 \pm \mathrm{I} .8$ \\
\hline
\end{tabular}

Table 2 Frequency of pre-pregnancy risk factors

\begin{tabular}{lll}
\hline & $\mathbf{n}$ & $\%$ \\
\hline Non-pathologic risk factors & & \\
Age $\leq 18$ years & 77 & 3.7 \\
Age $\geq 35$ years & 381 & 18.3 \\
Single or not living with a partner & 550 & 26.4 \\
Height $\leq 150 \mathrm{~cm}$ & 26 & 1.2 \\
Primiparity & 761 & 36.5 \\
Multiparity $\geq 5$ & 224 & 10.7 \\
Pathologic risk factors & & \\
Hypertension in family & 716 & 34.3 \\
Diabetes in family & 440 & 21.1 \\
Previous tuberculosis & 80 & 3.8 \\
Personal diabetes & 29 & 1.4 \\
Drepanocytosis & 42 & 2 \\
Overweight/obesity & 456 & 21.9 \\
Previous miscarriage & 692 & 33.2 \\
Previous gestational diabetes & 7 & 0.3 \\
Previous preeclampsia/eclampsia & 191 & 9.2 \\
Previous premature rupture of membranes & 130 & 6.2 \\
Previous cesarean section & 328 & 15.7 \\
Previous postpartum hemorrhage & 273 & 13.1 \\
Previous prematurity & 37 & 1.8 \\
Previous stillbirth & 65 & 3.1 \\
Previous low birth weight & 208 & 10 \\
Previous macrosomia & 208 & 10 \\
\hline
\end{tabular}

pregnancy are presented in Table 3. Almost all pathologic situations had a certain proportion of recurrence, the rates being 21/37 (57\%), 111/208 (53\%), 74/208 (36\%), 191/598 (32\%), 132/466 (28\%), 24/130 (18\%), and 4/65 (6\%) for prematurity, LBW, macrosomia, PEE, cesarean section, PROM, and stillbirth, respectively.

In unadjusted OR calculation (logistic regression analysis), only recurrence of PEE, cesarean section, PROM, and macrosomia were found to be significantly influenced by pre-pregnancy risk factors. So maternal age $\geq 35$ years, overweight/obesity, hypertension in family, previous cesarean section, previous PROM, previous macrosomia, previous

Table 3 Maternal and perinatal outcomes during current/justterminated pregnancy

\begin{tabular}{lll}
\hline & $\mathbf{n}$ & $\%$ \\
\hline Maternal outcomes & & \\
Premature rupture of membranes & 226 & 10.8 \\
Preeclampsia/eclampsia & 372 & 17.8 \\
Urinary infection & 700 & 33.6 \\
Cesarean section & 466 & 22.3 \\
Postpartum hemorrhage & 254 & 12.2 \\
Perinatal outcomes & & \\
Prematurity & 293 & 14 \\
Apgar score $<7$ & 229 & 11 \\
Low birth weight & 218 & 10.5 \\
Stillbirth & 50 & 2.4 \\
Macrosomia & 110 & 5.3 \\
Neonatal distress & 105 & 5 \\
\hline
\end{tabular}


Table 4 Risk factors influencing recurrence of adverse maternal and perinatal outcomes

\begin{tabular}{lllll}
\hline Recurring outcomes & Risk factors & P-value & Unadjusted OR (95\% Cl) & Adjusted OR (95\% Cl) \\
\hline PEE & Maternal age $\geq 35$ years & 0.006 & $1.7(I .2-2.6)$ & $1.6(I . I-2.4)$ \\
& Hypertension in family & 0.003 & $1.7(I .2-2.3)$ & $0.5(0.3-0.9)^{*}$ \\
& Previous CS & 0.004 & $1.8(1.2-2.6)$ & $1.7(1 . I-2.5)$ \\
CS & Previous PROM & 0.001 & $15.9(2.02-26.4)$ & $20.7(2.1-199.9)$ \\
& Previous stillbirth & 0.000 & $23.1(3.0-178.2)$ & $19.6(2.4-163.3)$ \\
Prematurity & Previous macrosomia & 0.000 & $5.7(2.7-12.1)$ & $3.2(1.4-7.6)$ \\
PROM & Previous PROM & 0.05 & $7.5(0.8-68.9)^{*}$ & $3.3(1.7-6.3)$ \\
& Previous miscarriage & 0.01 & $3.6(1.4-9.8)$ & $1.3(0.5-3.3)^{*}$ \\
Macrosomia & Previous macrosomia & 0.04 & $2.9(1.02-8.5)$ & $3.0(1.04-8)$ \\
LBW & Overweight/obesity & 0.003 & $2.5(1.3-4.8)$ & $2.3(1.2-4.5)$ \\
\hline
\end{tabular}

Note: *Not significant (OR $<1.5$ or $95 \% \mathrm{Cl}$ containing I).

Abbreviations: $\mathrm{Cl}$, confidence interval; CS, cesarean section; LBW, low birth weight; OR, odds ratio; PEE, preeclampsia/eclampsia; PPH, postpartum hemorrhage; PROM, premature rupture of membranes.

miscarriage, and stillbirth were pre-pregnancy risk factors that were significantly linked to recurrence of pregnancy complications (Table 4).

Logistic regression to establish independent influence (adjusted OR) of each prominent risk factor on recurrence of specific complications showed recurrence of PEE to be augmented by maternal age $\geq 35$ years (OR 1.6, 95\% CI: 1.1-2.4), previous cesarean section (OR 1.7, 95\% CI: 1.1-2.4), and previous PROM (OR 16, 95\% CI: 2-26); recurrence of cesarean section was augmented by previous stillbirth (OR 23.1, 95\% CI: 3-178) and previous macrosomia (OR 3.2, 95\% CI: 1.4-7.6). Only previous PROM increased the recurrence of prematurity (OR 3.3, 95\% CI: 1.7-6.3). Obesity was found to augment the recurrence of macrosomia (OR 2.3, 95\% CI: $1.2-4.5$ ). No factor was found to significantly infuence the recurrence of stillbirth.

Regarding direct relationships between pre-pregnancy risk factors and current pregnancy outcomes through unadjusted logistic regression (Table 5), complications such as urinary infection, hypertensive disorders, PROM, cesarean section, PPH, prematurity, neonatal distress, stillbirth, and macrosomia that were significantly influenced by nonpathologic risk factors were also significantly influenced by pathologic risk factors.

Primiparity and previous miscarriage had the weakest links with adverse outcomes. They were excluded from the adjusted logistic regression that was carried out to establish the effects of combinations of pathologic and non-pathologic variables on outcomes. Taking three non-pathologic factors (single status, multiparity $\geq 5$, and maternal age $\geq 35$ years) we progressively included the most prominent pathologic factors as covariates (Table 6).

After adjustment for non-pathologic factors, the effect of pathologic factors on outcomes either increased or decreased, but remained significant. Only the effect of previous $\mathrm{PPH}$ on PEE (bold value in Table 6) disappeared when considered according to single status. Nonetheless, non-pathologic variables remained independently associated with pregnancy complications.

\section{Discussion}

Antenatal surveillance may prevent or treat many complications that can lead to death. As such, current high rates of maternal and perinatal mortality in Democratic Republic of Congo, in spite of relatively high antenatal care attendance, ${ }^{15}$ indicate, at least in part, that more attention should be paid by caregivers to recognition of risk situations. Since a large number of women attending antenatal care are seen only once, our study aimed to determine how pre-pregnancy risk factors present at the first antenatal visit might predict pregnancy outcomes.

Major factors identified in our study as non-pathologic were primiparity, grand multiparity, single status, and maternal age $\geq 35$ years, which are well known to put a pregnancy at risk. ${ }^{8-10}$ These factors significantly influenced the occurrence of complications such as urinary infection, hypertensive disorders, PROM, cesarean section, PPH, prematurity, neonatal distress, stillbirth, and macrosomia. Corroborating previous literature, Mgaya et al,${ }^{18}$ in Tanzania, recently reported that grand multiparity was independently associated with an increased prevalence of malpresentation, fetal and neonatal distress, and placenta previa. In a rural area in Zimbabwe, Majoko et al ${ }^{19}$ reported primiparity to be a risk factor for LBW, cesarean section, and hypertensive disorders, whereas grand multiparity and young age were risk factors for hypertensive disorders and LBW, respectively. Young age was also linked to perinatal death. ${ }^{19}$ Although isolated non-pathologic risk factors have been reported to be linked to 


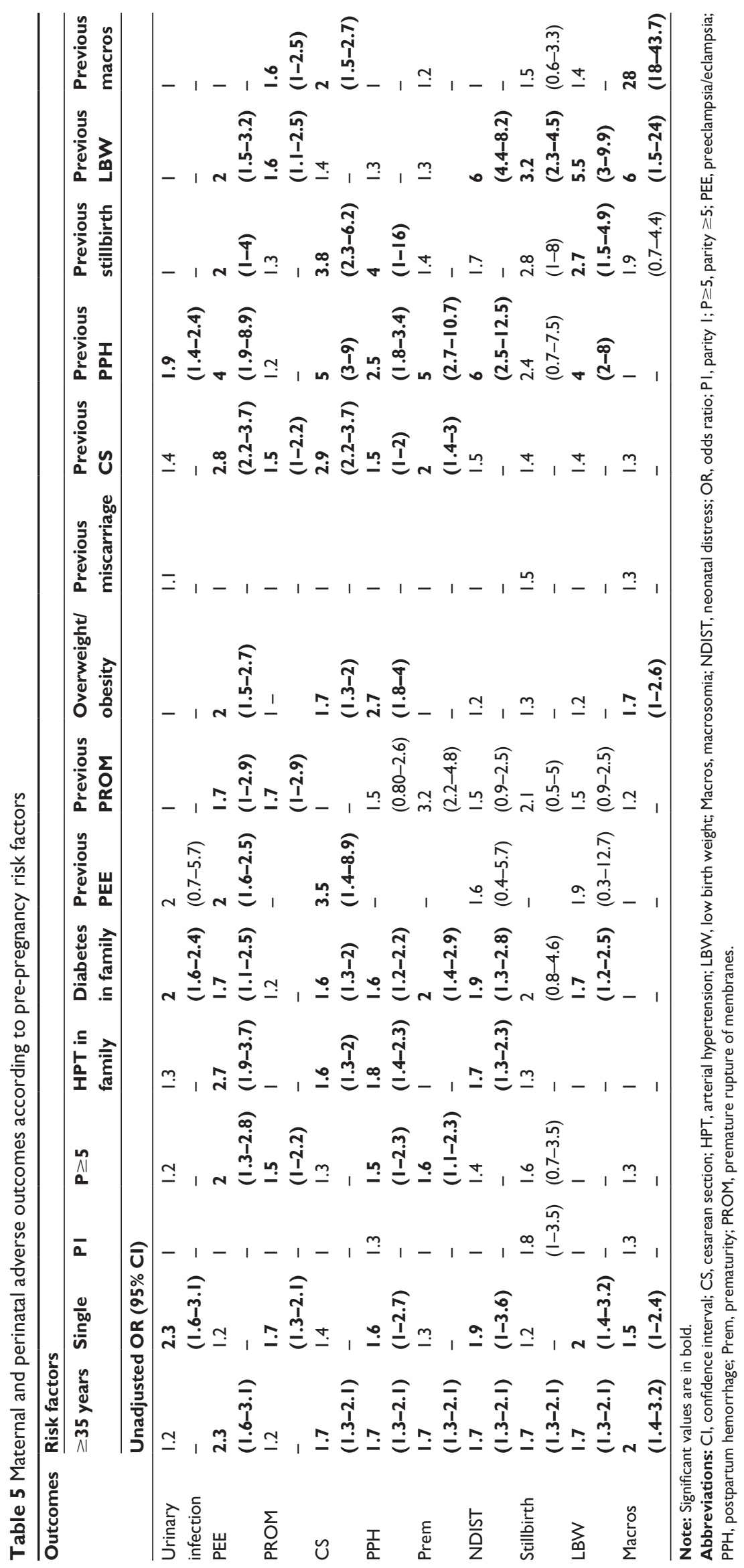


Table 6 Adverse outcomes according to main pathologic factors adjusted for non-pathologic risk variables (age $\geq 35$ years, single status, and parity $\geq 5$ )

\begin{tabular}{|c|c|c|c|c|c|c|c|c|c|c|}
\hline \multirow[t]{2}{*}{ Outcomes } & \multirow[t]{2}{*}{ PRFs } & \multicolumn{3}{|c|}{ Model I (age $\geq 35$ years) } & \multicolumn{3}{|c|}{ Model 2 (single status) } & \multicolumn{3}{|c|}{ Model 3 (parity $\geq 5$ ) } \\
\hline & & OR & $\mathrm{Cl}$ & & OR & $\mathbf{C l}$ & & OR & $\mathbf{C l}$ & \\
\hline \multirow[t]{2}{*}{ Urinary infection } & Diabetes in family & 2.0 & 1.6 & 2.4 & 1.9 & 1.6 & 2.4 & 2.0 & 1.6 & 2.4 \\
\hline & Prev PPH & 1.9 & 1.4 & 2.4 & 1.8 & 1.4 & 2.4 & 1.8 & $\mathrm{I} .4$ & 2.4 \\
\hline \multirow[t]{4}{*}{ PEE } & HPT in family & 1.7 & 1.3 & 2.1 & 1.6 & 1.3 & 2.0 & 1.6 & 1.3 & 2.1 \\
\hline & Prev PEE & 2.0 & 1.6 & 2.5 & 1.9 & 1.5 & 2.4 & 2.0 & 1.6 & 2.5 \\
\hline & Prev CS & 1.9 & 1.4 & 2.5 & 1.9 & 1.4 & 2.5 & 1.9 & 1.4 & 2.5 \\
\hline & Prev PPH & 1.5 & I.I & 2.0 & 1.4 & I.I & 1.9 & 1.5 & 1.1 & 2.0 \\
\hline \multirow[t]{3}{*}{ PROM } & Prev PROM & 2.0 & 1.3 & 3.3 & 1.9 & 1.2 & 3.0 & 1.8 & I.I & 2.9 \\
\hline & Prev LBW & 1.7 & 1.1 & 2.5 & 1.6 & I.I & 2.4 & 1.6 & I.I & 2.4 \\
\hline & Prev macrosomia & 1.7 & 1.2 & 2.6 & 1.6 & I.I & 2.4 & 1.6 & 1.1 & 2.4 \\
\hline \multirow[t]{4}{*}{ CS } & Overweight/obesity & 1.6 & 1.2 & 2.0 & 1.5 & 1.2 & 1.9 & 1.6 & 1.3 & 2.1 \\
\hline & Prev CS & 2.9 & 2.2 & 3.7 & 2.9 & 2.3 & 3.7 & 2.9 & 2.3 & 3.7 \\
\hline & Prev stillbirth & 3.7 & 2.2 & 6.0 & 3.5 & 2.1 & 5.8 & 3.8 & 2.3 & 6.2 \\
\hline & Prev macrosomia & 1.8 & 1.3 & 2.5 & 1.9 & 1.4 & 2.6 & 2.0 & 1.4 & 2.7 \\
\hline \multirow[t]{5}{*}{$\mathrm{PPH}$} & HPT in family & 1.8 & 1.4 & 2.3 & 1.7 & 1.3 & 2.2 & 1.8 & $\mathrm{I} .4$ & 2.3 \\
\hline & Diabetes in family & 1.6 & 1.2 & 2.2 & 1.5 & I.I & 2.1 & 1.6 & 1.2 & 2.2 \\
\hline & Prev PEE & 1.7 & 1.3 & 2.3 & 1.7 & 1.3 & 2.2 & 1.7 & 1.3 & 2.3 \\
\hline & Prev CS & 1.5 & $\mathrm{I} . \mathrm{I}$ & 2.1 & 1.5 & I.I & 2.1 & 1.5 & 1.1 & 2.1 \\
\hline & Prev PPH & 2.5 & 1.8 & 3.4 & 2.4 & 1.7 & 3.3 & 2.5 & 1.8 & 3.5 \\
\hline \multirow[t]{2}{*}{ Prematurity } & Prev PROM & 3.3 & 2.2 & 4.9 & 2.9 & 2.0 & 4.3 & 3.0 & 2.0 & 4.5 \\
\hline & Prev LBW & 6.0 & 4.4 & 8.2 & 5.7 & 4.1 & 7.8 & 5.8 & 4.3 & 8.0 \\
\hline NDIST & Prev LBW & 3.2 & 2.2 & 4.5 & 3.1 & 2.2 & 4.4 & 3.1 & 2.2 & 4.5 \\
\hline Stillbirth & Prev LBW & 5.3 & 2.9 & 9.6 & 5.2 & 2.9 & 9.5 & 5.3 & 2.9 & 9.7 \\
\hline \multirow[t]{2}{*}{ LBW } & Prev stillbirth & 2.6 & 1.5 & 4.8 & 2.6 & 1.4 & 4.7 & 2.7 & 1.5 & 4.9 \\
\hline & Prev LBW & 18.9 & 13.5 & 26.5 & 19.1 & 13.6 & 26.8 & 19.8 & 14.1 & 27.9 \\
\hline \multirow[t]{2}{*}{ Macrosomia } & Overweight/obesity & 1.6 & 1.0 & 2.4 & 1.6 & I.I & 2.5 & 1.6 & I.I & 2.5 \\
\hline & Prev macrosomia & 27.8 & 17.8 & 43.4 & 28.5 & 18.3 & 44.3 & 28.4 & 18.3 & 44.1 \\
\hline
\end{tabular}

Abbreviations: CS, cesarean section; HPT, arterial hypertension; LBW, low birth weight; NDIST, neonatal distress; OR, odds ratio; PEE, preeclampsia/eclampsia; $\mathrm{PPH}$, postpartum hemorrhage; Prev, previous; PRFs, pathologic risk factors; PROM, premature rupture of membranes; $\mathrm{Cl}$, confidence interval.

adverse outcomes, previous literature specifically considering these in comparison with pathologic factors, in terms of their relationships with both maternal and perinatal complications, is lacking. In our study, the ability of non-pathologic factors to consistently predict adverse outcomes even in the absence of previous pregnancy complications emphasizes their role in identifying primiparae in need of referral.

Factors that dominated among pathologic risk factors in our series were family history of hypertension and diabetes, previous PROM, previous cesarean section, previous PPH, previous LBW, and previous macrosomia, along with obesity. Major complications experienced during current/ just-terminated pregnancy were also significantly linked to pathologic risk factors. The latter were found to be likely to enhance the effect of non-pathologic factors. This could be explained by the strong potential of previous cesarean section, PROM, and stillbirth to augment recurrence of cesarean section. Recurrence of prematurity was found to be increased by previous PROM, and obesity augmented recurrence of macrosomia. On the theoretical ground, the link between pathologic pre-pregnancy risk factors and adverse outcomes is easier to accept, although Stamilio et al ${ }^{5}$ failed to find any antenatal clinical and biochemical marker significantly predicting the development of severe preeclampsia. Duckitt and Harrington ${ }^{1}$ reported the risk of preeclampsia to be significantly increased by a previous history of preeclampsia, preexisting diabetes, multiple pregnancy, family history of hypertensive disease, and high BMI. ${ }^{1}$ Our study had similar findings as that of Duckitt and Harrington ${ }^{1}$ about previous history of miscarriage, PROM, cesarean section, and PPH. Poor results, however, were obtained regarding existing medical/surgical illnesses. This is not to minimize that having raised blood pressure before pregnancy increases the risk of hypertensive disorder during pregnancy. ${ }^{20} \mathrm{Haas}$ et $\mathrm{al}^{21}$ found that health status and risky behaviors prior to conception accounted for $40 \%$ of the variability in risk of preterm delivery.

Previous pregnancy complications were found to have a rate of recurrence (6\%-57\%) expected to serve for strong predictability and thence preventability. Maternal age $\geq 35$ years was the only non-pathologic variable to be involved in recurrence of hypertensive disorder. Either isolated or in 
combination, pathologic factors influenced the recurrence of complications: previous cesarean section, PROM, and PEE augmented the risk of PEE; previous stillbirth and macrosomia augmented that of cesarean section. Only previous PROM increased the recurrence of prematurity, and obesity was found to augment the recurrence of macrosomia. No factor was found to significantly infuence the recurrence of stillbirth or LBW. Majoko et $\mathrm{al}^{19}$ observed a high rate of recurrence of hypertensive disorders, operative delivery, and preterm delivery. Ouyang et al, ${ }^{22}$ recently reporting on recurrence of pregnancy complications in developing countries, noted that stillbirth at the first pregnancy put a woman at increased risk of the same outcome in her second pregnancy. This likelihood of recurrence represents a major factor that puts multiparae at additional risk of morbidity in comparison with primiparae. Therefore, long before admitting women for emergency situations during parturition, efforts should be directed to mitigation of pathologic risk factors that can be modified, conversely non-pathologic factors that cannot be mitigated. ${ }^{23}$ They are not to be ignored since they lead to more awareness so that adequate management can be planned. ${ }^{8}$ Primiparity, for instance, is more deleterious when associated with age $\geq 35$ years. Attempts to prevent hypertensive disorders, preterm labor, and LBW in women at increased risk might bring improvements regarding frequency of operative delivery and maternal/infant morbidity/mortality.

In developed countries it was established that skilled personnel, proper infrastructure in the labor ward and optimal care during delivery lead to good maternal and perinatal protection. In these countries, therefore, the role of antenatal care as recommended in developing countries seems to be neglected. We thus suppose that this is the main reason why literature still reporting on antenatal care in developed countries deals only with fetal grow restriction and stillbirth for which a proper antenatal survey is needed. In developing countries instead, we found that there are much more outcomes to be dealt with.

Our findings are in accordance with previous literature that supports the strategy of aiming at exclusion of poorly predictive risk factors from routine surveillance so that one can concentrate on key factors known to cause or precipitate death (hemorrhage, hypertensive disorders, infection, and disordered growth). ${ }^{8,24}$ The rate of antenatal attendance (95\%) observed in our setting is far from reflecting its quality but can be used to serve that strategy. Early or late, the first antenatal visit offers caregivers a crucial opportunity to identify those women in need of more than classical immunization options and preventive measures against potentially aggravating states (anemia, malaria, TORCH [toxoplasmosis, other infections, rubella, Cytomegalovirus infection, and herpes simplex virus], and genital tract infections, including HIV). Thanks to accurate assessment of pre-pregnancy risk factors, antenatal care remains one of four pillars of safe motherhood, the three others being family planning, clean/safe delivery, and essential obstetric care. ${ }^{25}$

Weaknesses of our study may lie in the lack of some factors claimed to influence pregnancy outcomes, such as education, socioeconomic and smoking statuses, interpregnancy interval, and all health conditions (nutrition; lung, heart, kidney, liver, thyroid, and autoimmune diseases; and infection status), which can all predispose pregnant women to certain complications. There are early outcomes not dealt with in the study but likely to be associated with risk factors, such as abortions, threatened abortions and other pregnancy complications occurring during the first half of pregnancy.

The main strength of our study is its large, populationbased sample. Since the study relates to main maternities in the capital city of Democratic Republic of Congo, its results are easily generalizable. Irrespective of study design, previous studies have demonstrated similar findings to the present study regarding the effects of pre-pregnancy risk factors on PEE, stillbirth, and neonatal mortality. Having demonstrated the same, additional strengths of our study lie in the fact that it:

- extends concern about pre-pregnancy risk factors to more complications than LBW and stillbirth, thus better corresponding to the issues of maternal/perinatal morbidity/ mortality in developing countries;

- shows that the ability of non-pathologic pre-pregnancy factors to predict pregnancy complications challenges that of pathologic factors, making them relevant even in women without any history of reproductive risk factors; and

- illustrates the potential of the only/first booking visit for building pregnancy risk strategies, especially when antenatal attendance rates do not meet standards $\mathrm{s}^{3,7,11,25}$ that recommend at least 3-4 antenatal visits.

\section{Conclusion}

This study demonstrated that pre-pregnancy high-risk factors are associated with an increased prevalence of a wide range of maternal and perinatal complications. The ability of nonpathologic factors to predict pregnancy complications challenges that of pathologic factors, making them relevant even in women without any reproductive history factor. This illustrates the potential of the only/first booking visit for building pregnancy risk strategies, mostly in a good referral system. 


\section{Acknowledgments}

BTU, MD, PhD, is Specialist in Obstetrics and Gynecology and Professor and Chief of the Department of Obstetrics and Gynecology, University of Kinshasa, Kinshasa, Democratic Republic of Congo. AMM, MD, is Specialist in Obstetrics and Gynecology and a member of the Department of Obstetrics and Gynecology, University of Kinshasa, Kinshasa, Democratic Republic of Congo. This study was presented in nine parts (corresponding to the nine sites of sampling) in March and May 2014, in order to fulfill the requirements for completion of their studies in medicine, by each of MBKK, AGKT, PKM, SKM, IKM, OKK, JKB, RKK, and SKK. The authors declare that they funded this study themselves.

\section{Author contributions}

All authors contributed toward data analysis, drafting and revising the paper and agree to be accountable for all aspects of the work.

\section{Disclosure}

The authors report no conflicts of interest in this work.

\section{References}

1. Duckitt K, Harrington D. Risk factors for pre-eclampsia at antenatal booking: systematic review of controlled studies. BMJ. 2005;12:330(7491):565.

2. Luguterah A, Nokoe KS. Pre-pregnancy risk factors for intrauterine fetal mortality in Ghana. American Journal of Public Health Research. 2013;1(5):124-128. Available from: http://pubs.sciepub.com/ajphr/1/5/3. Accessed.

3. Banta D. What is the Efficacy/Effectiveness of Antenatal Care and the Financial and Organizational Implications? Health Evidence Network Report. Copenhagen: WHO Regional Office for Europe; 2003. Available from: http://www.euro.who.int/Document/E82996.pdf. Accessed February 7, 2014.

4. Gardosi J, Madurasinghe V, Williams M, Malik A, Francis A. Maternal and fetal risk factors for stillbirth: population based study. BMJ. 2013;346:f108

5. Stamilio DM, Sehdev HM, Morgan MA, Propert K, Macones GA. Can antenatal clinical and biochemical markers predict the development of severe preeclampsia? Am J Obstet Gynecol. 2000;182(3):589-594.

6. Nylander PP, Adekunle AO. Antenatal care in developing countries. Baillieres Clin Obstet Gynaecol. 1990;4(1):169-186.

7. Abou Zahr CL, Wardlaw TM. Antenatal Care in Developing Countries: Promises, Achievements and Missed Opportunities: An Analysis of Trends, Levels and Differentials, 1990-2001. Geneva: World Health Organization; 2003.
8. Reddy UM, Laughon SK, Sun L, Troendle J, Willinger M, Zhang J. Prepregnancy risk factors for antepartum stillbirth in the United States. Obstet Gynecol. 2010;116(5):1119-1126.

9. Kristensen J, Vestergaard M, Wisborg K, Kesmodel U, Secher NJ. Pre-pregnancy weight and the risk of stillbirth and neonatal death. BJOG. 2005;112(4):403-408.

10. Bakketeig LS, Jacobsen G, Hoffman HJ, et al. Pre-pregnancy risk factors of small-for-gestational age births among parous women in Scandinavia. Acta Obstet Gynecol Scand. 1993;72(4):273-279.

11. Villar J, Bergsjø P. Scientific basis for the content of routine antenatal care. I. Philosophy, recent studies, and power to eliminate or alleviate adverse maternal outcomes. Acta Obstet Gynecol Scand. 1997;76(1):1-14

12. Hall MH, Chng PK, MacGillivray I. Is routine antenatal care worth while? Lancet. 1980;2(8185):78-80.

13. Onoh R, Umeora O, Agwu U, Ezegwui H, Ezeonu P, Onyebuchi A. Pattern and determinants of antenatal booking at abakaliki southeast Nigeria. Ann Med Health Sci Res. 2012;2(2):169-175.

14. Ebeigbe PN, Igberase GO. Reasons given by pregnant women for late initiation of antenatal care in the Niger delta, Nigeria. Ghana Med J. 2010;44(2):47-51.

15. Simkhada B, Teijlingen ER, Porter M, Simkhada P. Factors affecting the utilization of antenatal care in developing countries: systematic review of the literature. JAdv Nurs. 2008;61(3):244-260.

16. Democratic Republic of Congo. Demographic and Health Survey 2007. Kinshasa: Ministry of Planning; 2009.

17. Mbangama MA, Tandu-Umba B. Maternal nutritional status at term and risk of gestational diabetes mellitus. Diabetes Res Clin Pract. 2014;103:S50.

18. Mgaya AH, Massawe SN, Kidanto H, Mgaya HN. Grand multiparity: is it still a risk in pregnancy? BMC Pregnancy Childbirth. 2013;13:241.

19. Majoko F, Nyström L, Munjanja S, Lindmark G. Usefulness of risk scoring at booking for antenatal care in predicting adverse pregnancy outcome in a rural African setting. J Obstet Gynaecol. 2002;22(6): 604-609.

20. Hedderson MM, Darbinian JA, Sridhar SB, Quesenberry CP. Prepregnancy cardiometabolic and inflammatory risk factors and subsequent risk of hypertensive disorders of pregnancy. Am J Obst Gynecol. 2012;207(1):68. e1-e9.

21. Haas JS, Fuentes-Afflick E, Stewart AL, et al. Prepregnancy health status and the risk of preterm delivery. Arch Pediatr Adolesc Med. 2005;159(1):58-63.

22. Ouyang F, Zhang J, Betrán AP, Yang Z, Souza JP, Merialdi M. Recurrence of adverse perinatal outcomes in developing countries. Bull World Health Organ. 2013;91:357-367.

23. Stillbirth Collaborative Research Network Writing Group. Association between stillbirth and risk factors known at pregnancy confirmation. JAMA. 2011;306(22):2469-2479.

24. Oyerinde K. Can antenatal care result in significant maternal mortality reduction in developing countries? J Community Med Health Educ. 2013;3(2):2-3.

25. Bergsjø P. What Is the Evidence for the Role of Antenatal Care Strategies in the Reduction of Maternal Mortality and Morbidity? Reduction of Maternal Mortality: A Joint WHO/UNFPA/UNICEF/World Bank Statement. Geneva: World Health Organization; 1999.
International Journal of Women's Health

\section{Publish your work in this journal}

The International Journal of Women's Health is an international, peerreviewed open-access journal publishing original research, reports, editorials, reviews and commentaries on all aspects of women's healthcare including gynecology, obstetrics, and breast cancer. The manuscript management system is completely online and includes

\section{Dovepress}

a very quick and fair peer-review system, which is all easy to use Visit http://www.dovepress.com/testimonials.php to read real quotes from published authors. 